\title{
Population structure and uropathogenic potential of extended-spectrum cephalosporin-resistant Escherichia coli from retail chicken meat
}

May Linn Buberg ${ }^{1 \dagger}$, Solveig Sølverød $\mathrm{Mo}^{2 \dagger}$, Camilla Sekse ${ }^{2}$, Marianne Sunde ${ }^{2}, Y_{n g v i l d ~ W a s t e s o n}{ }^{2}$ and Ingun Lund Witsø $\varnothing^{1 *}$

\begin{abstract}
Background: Food-producing animals and their products are considered a source for human acquisition of antimicrobial resistant (AMR) bacteria, and poultry are suggested to be a reservoir for Escherichia coli resistant to extended-spectrum cephalosporins (ESC), a group of antimicrobials used to treat community-onset urinary tract infections in humans. However, the zoonotic potential of ESC-resistant E. coli from poultry and their role as extraintestinal pathogens, including uropathogens, have been debated. The aim of this study was to characterize ESC-resistant E. coli isolated from domestically produced retail chicken meat regarding their population genetic structure, the presence of virulence-associated geno- and phenotypes as well as their carriage of antimicrobial resistance genes, in order to evaluate their uropathogenic potential.
\end{abstract}

Results: A collection of 141 ESC-resistant E. coli isolates from retail chicken in the Norwegian monitoring program for antimicrobial resistance in bacteria from food, feed and animals (NORM-VET) in 2012, 2014 and 2016 ( $n=141$ ) were whole genome sequenced and analyzed. The 141 isolates, all containing the beta-lactamase encoding gene bla $a_{\mathrm{CMY}-2}$, were genetically diverse, grouping into 19 different sequence types (STs), and temporal variations in the distribution of STs were observed. Generally, a limited number of virulence-associated genes were identified in the isolates. Eighteen isolates were selected for further analysis of uropathogen-associated virulence traits including expression of type 1 fimbriae, motility, ability to form biofilm, serum resistance, adhesion- and invasion of eukaryotic cells and colicin production. These isolates demonstrated a high diversity in virulence-associated phenotypes suggesting that the uropathogenicity of ESC-resistant E. coli from chicken meat is correspondingly highly variable. For some isolates, there was a discrepancy between the presence of virulence-associated genes and corresponding expected phenotype, suggesting that mutations or regulatory mechanisms could influence their pathogenic potential.

\footnotetext{
* Correspondence: ingun.lund.witso@nmbu.no

${ }^{\dagger}$ May Linn Buberg and Solveig Sølverød Mo contributed equally to this work.

${ }^{1}$ Department of Paraclinical Sciences, Faculty of Veterinary Medicine,

Norwegian University of Life Sciences, Oslo, Norway

Full list of author information is available at the end of the article
}

C C The Author(s). 2021 Open Access This article is licensed under a Creative Commons Attribution 4.0 International License, which permits use, sharing, adaptation, distribution and reproduction in any medium or format, as long as you give appropriate credit to the original author(s) and the source, provide a link to the Creative Commons licence, and indicate if changes were made. The images or other third party material in this article are included in the article's Creative Commons licence, unless indicated otherwise in a credit line to the material. If material is not included in the article's Creative Commons licence and your intended use is not permitted by statutory regulation or exceeds the permitted use, you will need to obtain permission directly from the copyright holder. To view a copy of this licence, visit http://creativecommons.org/licenses/by/4.0/. The Creative Commons Public Domain Dedication waiver (http://creativecommons.org/publicdomain/zero/1.0/) applies to the data made available in this article, unless otherwise stated in a credit line to the data. 
(Continued from previous page)

Conclusion: Our results indicate that the ESC-resistant E. coli from chicken meat have a low uropathogenic potential to humans, which is important knowledge for improvement of future risk assessments of AMR in the food chains.

Keywords: Antimicrobial resistance, AMR, Poultry, Foodborne, Norway, Phenotype, E. coli, Virulence, Urinary tract infection, UTI

\section{Background}

Escherichia coli is a highly diverse species that includes commensals, pathogens, and opportunistic pathogens. $E$. coli that cause infections outside the intestinal tract are commonly referred to as extraintestinal pathogenic $E$. coli (ExPEC). ExPEC is usually phenotypically indistinguishable from gut-colonizing commensal E. coli. Based on their virulence traits, they are often divided into subgroups such as uropathogenic E. coli (UPEC), isolates causing septicemia, neonatal meningitis-causing $E$. coli (NMEC), and avian pathogenic E. coli (APEC) [1, 2]. As ExPEC are mainly considered opportunistic pathogens, it has been challenging to define a set of virulence factors for this group of bacteria. Terms like "fitness factors", "colonizing factors", and "virulence-associated traits" have been suggested as being more accurate for describing specific traits that distinguish ExPEC from other E. coli [2-4]. Johnson et al. proposed a list of ExPEC virulence-associated traits which included various adhesins, toxins, nutritional characteristics, protectins, and miscellaneous traits [3]. The common denominator for all these traits is provision of competitive advantages and survival outside the intestinal tract, with potential to cause disease in various other tissues [2-4]. Several reservoirs for ExPEC have been described, for example the intestinal tract of humans, companion animals, and food-producing animals [5]. Different typing methods have been applied for epidemiological purposes and understanding of the transmission of ExPEC between different reservoirs and hosts, allowing for differentiation of $E$. coli into group levels. Multilocus sequence typing (MLST) groups E. coli into various sequence types (STs), and some STs are known to possess a higher pathogenic potential than others [6].

Urinary tract infection (UTI) is one of the most common bacterial infections encountered in the human population worldwide, and comes with great societal costs [7]. A UTI starts with bacteria, such as UPEC, colonizing the distal parts of the urethra, thereby ascending into the bladder, adhering to the surface of the bladder, followed by biofilm formation, and then invasion and replication within the hosts cells [8-10]. Both structural and secretory features are involved in UPECs ability to cause UTI [8]. Structural virulence-associated traits including adhesins, fimbriae, flagella, and other surface components are involved in colonization of the mucosal surfaces in the urinary tract, while secreted components, such as toxins and enzymes, are responsible for cell-damage [11]. UTIs can vary from a mild bacteriuria to severe urosepsis, and antimicrobials are often needed for curing the infection [12].

Antimicrobial resistance (AMR) is one of the largest threats against global public health in our time [13, 14]. Use of antimicrobials is regarded as the most important driver for development and dissemination of AMR, although the exact and relative amounts distributed to and between human and veterinary medicine vary considerably from country to country [15-17]. On a global basis, the use and overuse of antimicrobials in foodproducing animals is extensive, and the co-occurrence of AMR, including extended-spectrum cephalosporin (ESC)-resistant E. coli, in the food chains is considerable $[15,17,18]$. The Norwegian monitoring program for antimicrobial resistance in bacteria from food, feed, and animals (NORM/NORM-VET) have for several years documented that Norway is among the European countries with the lowest levels of antimicrobial use and corresponding low levels of AMR $[13,14,19,20]$. NORMVET is governed by the legislation ensuring harmonized AMR monitoring within the EU, and poultry are sampled every other year [21]. Results document that the Norwegian broiler production has a low level of antimicrobial use with only one to seven flocks treated yearly between 2013 and 2017 [22-27]. ESC-resistant E. coli have nevertheless been detected in healthy broilers and retail chicken meat using selective methods since their first observed appearance in 2006, and with significant reduction since 2012 [28, 29].

Food-producing animals and their products are considered a possible source for human acquisition of AMR E. coli [30-32]. ESC-resistant E. coli isolates are of particular interest, as extended-spectrum cephalosporins are listed as critically important antimicrobials by the World Health Organization [33]. Genetic comparisons of $E$. coli isolates from poultry and clinical UPEC isolates have been observed to have a high degree of similarity [34], and E. coli isolates from meat have also been shown to cause UTI in murine models [35]. In a review from 2015, Lazarus et al. considered poultry to be the most likely source of human acquisition of ESC-resistant 
ExPEC from food-producing animals [36], and consumption of chicken meat could thus be a possible route of ExPEC transmission, including UPECs [35-38]. In a report from 2015 the Norwegian Scientific Committee for Food and Environment (VKM) also concluded that poultry and poultry products are regarded as the most important reservoirs of ESBL/AmpC-producing Enterobacteriaceae, quinolone resistant E.coli (QREC), and their corresponding resistance determinants [39]. However, lack of data has made it difficult to reach any firm conclusions regarding the probability of AMR transmission from food to humans.

The aim of this study was to characterize ESCresistant E. coli isolated from domestically produced retail chicken meat regarding their population genetic structure, the presence of virulence-associated geno- and phenotypes as well as their carriage of AMR genes, in order to evaluate their uropathogenic potential. To ensure a highly relevant collection of bacterial isolates, all ESC-resistant E. coli isolates collected from retail chicken meat through NORM-VET in 2012, 2014, and 2016 were included in the initial screening and description. Representative isolates were selected for further phenotypic virulence characterization.

\section{Results}

\section{Characterization of population structure}

All the 141 ESC-resistant isolates were whole genome sequenced and the isolates were grouped into 19 different sequence types (STs) based on 7-gene MLST. A core genome (cg) MLST including 2360 genes clustered each ST separately (Fig. 1). There was an annual variation in the presence of STs; ST38 was the most common ST in both $2012(n=57,86 \%)$ and $2014(n=16,28 \%)$ but was not detected in 2016. A total of 241 allele differences were present among the 73 ST38 isolates, and none of the isolates displayed identical cgMLST profiles. ST1158 was also common among isolates collected in 2014 $(n=$ 15, 26\%). However, this ST was not present in either 2012 or 2016. Fifty allele differences were detected among isolates belonging to ST1158, and two isolates shared an identical cgMLST profile. In 2016, ST2040 emerged as a new ST, and was also the dominant ST that year $(n=11,65 \%)$. A total of 32 allele differences were observed between the isolates belonging to ST2040, with two isolates displaying identical cgMLST profiles. The highest diversity of STs was observed in 2014, with 12 different STs being represented among the isolates, followed by seven different STs in 2012, and five in 2016. Two STs were present in all three years, namely ST10 $(n=3+2+1)$ and ST1594 $(n=1+1+1)$. In the cgMLST analysis, 39 and 44 allele differences were detected among ST10 and ST1594 isolates, respectively. None of the ST10 nor the ST1594 isolates shared identical cgMLST patterns (Fig. 1). An overview of the results from the ST-profiling is presented in Fig. 2.

\section{Virulence-associated geno- and phenotypes}

In order to study the virulence potential of the 141 ESC isolates we used Virulence Finder and vfdb_core databases to detect virulence genes. Based on the authors' knowledge and descriptions in the databases specific UPEC-associated virulence genes were identified. A complete overview of all virulence genes identified in each of the 141 isolates investigated is found in the Supplementary material (Table S1). In general, a limited number of genes encoding UPEC-associated virulence factors were present among the isolates. Genes encoding the UPEC-associated toxins hemolysin $(h l y)$ or cytotoxic necrotizing factor 1 (cnf1) were not identified in any of the isolates. The most common UPEC-associated virulence genes detected among the $E$. coli isolates encoded proteins involved in iron uptake, synthesis of type $1 \mathrm{fim}$ briae, serum survival, and capsule formation (Table S1). Furthermore, incomplete operons encoding certain traits, such as P-fimbriae (papA-K) and type 1 fimbriae ( im $A-I)$ were identified in several isolates.

To evaluate the expression of detected genes and virulence-potential, a selection of isolates was chosen for further phenotypical testing. These isolates were selected based on the following criteria: 1) representatives from each phylogroup (A, B1, B2, or D) and different sequence types, 2) isolates with the most and the fewest virulence genes, 3) representatives from the most prevalent sequence types, 4) at least one representative from common ExPEC STs. An overview of these 18 isolates and their UPEC- and AMR-associated genes are summarized in Table 1. A summary of the results from the in vitro phenotypic tests related to the presence of selected virulence-associated genes is presented in Fig. 3. In total, there was limited consistency between the occurrence of genes and the corresponding traits detected in the in vitro phenotypic assays.

Expression of the type 1 fimbriae was assessed by a yeast agglutination test which tests the ability of type 1 fimbriated bacteria to bind to mannose receptors on the surface of yeast cells. Seven out of 18 isolates did not agglutinate the yeast cells. Among the remaining 11 positive isolates, six harbored the complete fim $A$ - I operon, while at least one of the genes in the fim operon was not detected in the other five. Among the seven isolates that were not able to agglutinate yeast cells, a complete fim operon was identified in two isolates (Fig. 3).

To be able to migrate from the gastrointestinal tract to other tissues, resistance to killing by human serum provides a huge advantage for bacterial survival. None of the isolates were classified as sensitive in the serumresistance assay. Most of the isolates exhibited 


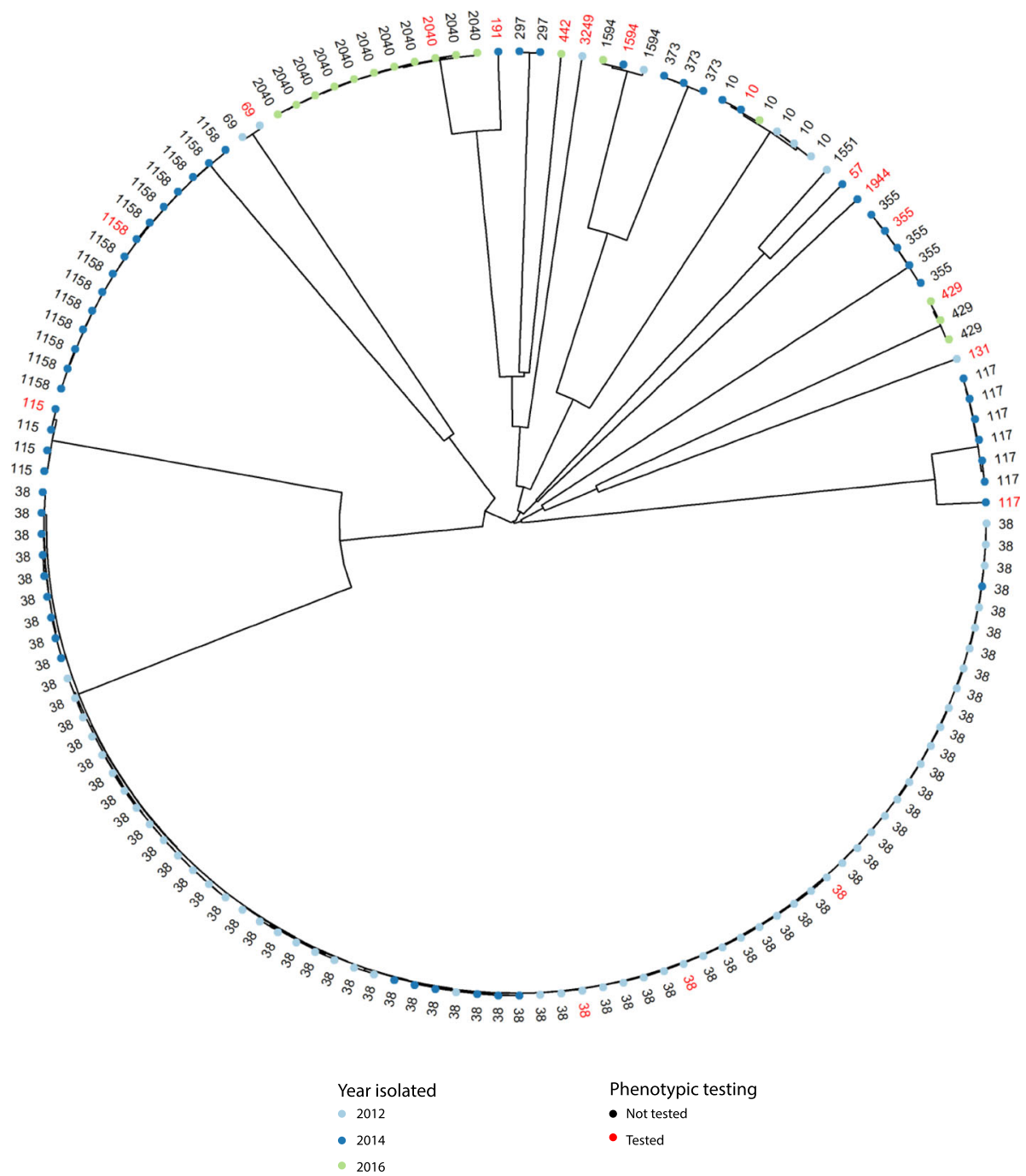

Fig. 1 Clustering of 141 ESC-resistant Escherichia coli isolated from Norwegian retail chicken meat. The clustering is based on core genome multilocus sequence typing. Year isolated is indicated as light blue (2012), blue (2014), or light green (2016) dots. The 18 isolates marked in red were included in the in vitro virulence assays

intermediate serum resistance $(n=10)$, whereas the remaining isolates were resistant to inactivation by human serum. Five of the resistant isolates and six of the isolates that exhibited intermediate resistance harbored the iss gene.

Production of colicins can provide competitive advantages by inhibiting growth of other coliform bacteria, ensuring the isolate to prevail. Thirteen isolates produced colicins. The most prevalent colicin-encoding gene detected among the $E$. coli isolates was cma, encoding Colicin M. The cma gene was present in eight of the colicin-producing isolates. In two of these isolates, $\mathrm{cma}$ was found in combination with $c e l B$ (Colicin E2) and $c b a$ (Colicin $\mathrm{B}$ ), in two isolates in combination with only celB or in combination with $m c h B, m c h C$ and $m c h F$ (Microcin H47), respectively. One of the colicin- producing isolates carried only the $c e l B$ gene, while $c e l B$ was present in combination with $m c h B$ and $m c h C$ in another isolate. There was also one isolate that only carried the $m c m A$ gene (Microcin M/Colicin V). Finally, there were two colicin-producing isolates which did not carry any of the investigated colicin-encoding genes. In four of the five isolates without colicin production, genes associated with colicin production were identified (Fig. 3).

We wanted to characterize the potential of our isolates to colonize a host. Thus, the ability to adhere to and invade Vero cells were studied. The isolates showed a high capability of bacterial adhesion to eukaryotic cells, but low capability of cell invasion. Data for cell adhesion and invasion for isolate 2016-22-220 (ST429) is not included in the results as concentrations of antibiotics used to kill adherent bacteria were not effective for this isolate, 


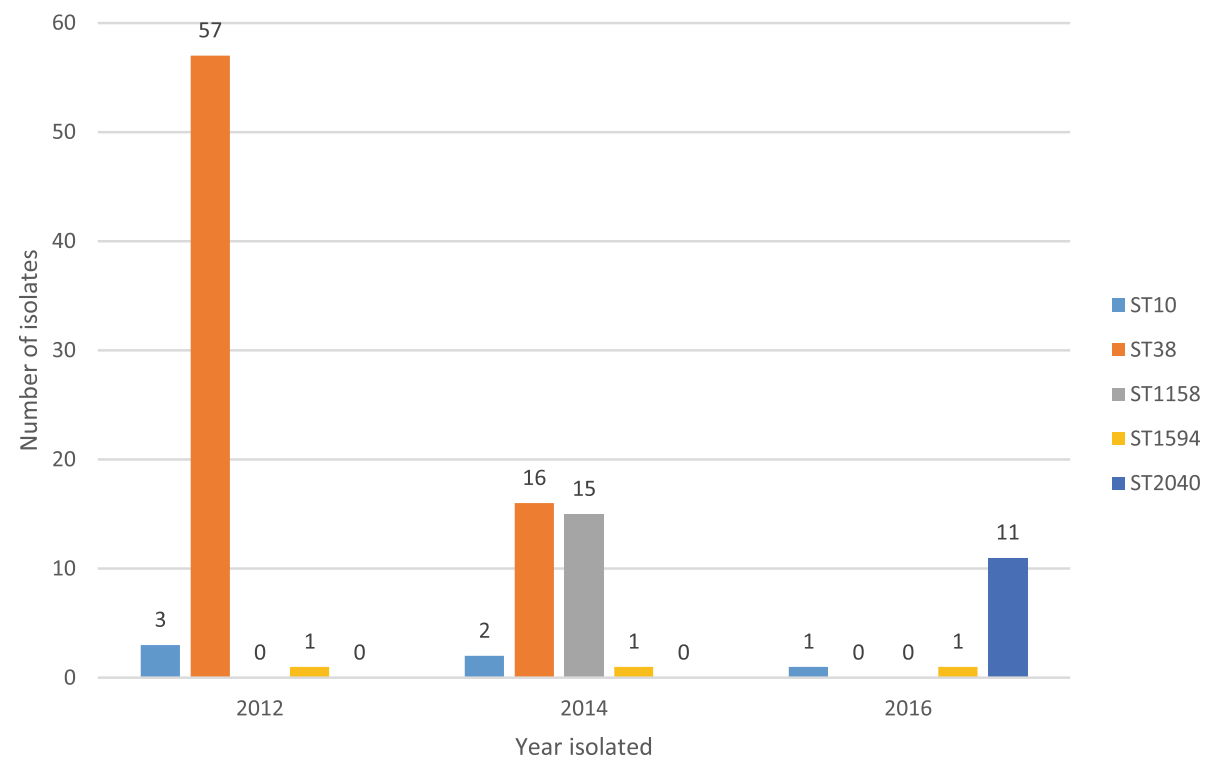

Fig. 2 Fluctuation in selected sequence types during 2012, 2014, and 2016. The figure illustrates the distribution of Escherichia coli isolates belonging to the three most common sequence types, namely ST38, ST1158, and ST2040 in 2012, 2014, and 2016. Furthermore, the number of isolates grouping into ST10 and ST1594 is illustrated, as these were the only sequence types present in all three years

despite exceeding the predicted MIC values. Several genes may be involved in the process of cell adhesion. Genes investigated in this study include the $s f a X$ gene, the pap operon and the fim operon. In only one of the isolates, 2014-01-3678 (ST117), both the sfaX gene and a complete pap operon were identified. However, an incomplete fim operon was also identified in the same isolate. This isolate displayed a high degree of cell adhesion ( $>400 \mathrm{CFU} / \mathrm{ml}$ ). The degree of cell adhesion among the eight isolates with a complete fim operon was observed to be very variable. Although isolate 2014-01-4991 (ST57) carried incomplete fim- and pap operons, and the $s f a X$ gene was absent it showed a high degree of cell adhesion.

Motility was evaluated as the ability of the bacteria to move through semi-liquid LB agar. None of the isolates were able to move in $0.7 \%$ agar. Eight of the isolates were non-motile in $0.2 \%$ agar, but only isolate 2014-017011 (ST1944) was non-motile in $0.03 \%$ agar. The ability to form biofilm varied among the isolates, between temperatures and culture incubation times. Biofilm production was defined by OD three times as high as the control. Isolate 2012-01-707 (ST38) produced the strongest biofilm at $37^{\circ} \mathrm{C}$, while isolate 2016-22-1061 (ST2040) was the strongest biofilm producer at $20^{\circ} \mathrm{C}$. Nine of the isolates displayed poor biofilm formation at both $37^{\circ} \mathrm{C}$ and $20^{\circ} \mathrm{C}$. All isolates were able to grow in human urine (Fig. 4). Isolate 2016-22-1061 (ST2040) exhibited the most rapid growth of the 18 isolates, given the experimental conditions provided, both in urine and in LB. Growth rates are provided in the supplementary material (Table S2).

\section{Acquired AMR genes}

The presence of $b l a_{\mathrm{CMY}-2}$ in all isolates was confirmed by the WGS data, and some of the isolates carried additional resistance genes. These included ampicillin-resistance gene bla ${ }_{\mathrm{TEM} 1 \mathrm{~B}} \quad(n=13)$, sulfonamide-resistance genes sul1 $(n=5)$ and sul2 $(n=11)$, streptomycin- and spectinomycin-resistance gene $\operatorname{aadA1}(n=6)$, aminoglycoside-resistance genes aac (3)-VIa $(n=3)$ and aph $(n=2)$, tetracyclineresistance genes $\operatorname{tet}(\mathrm{A})(n=3)$ and $\operatorname{tet}(\mathrm{B})(n=2)$, and trimethoprim-resistance genes $d f r A 1(n=2)$ and $d f r A 5$ $(n=1)$. In general, isolates with the same ST had highly similar AMR genes. An overview of acquired AMR genes and their association with ST in all included isolates is presented in the Supplementary material (Fig. S1 and Table S1).

\section{Discussion}

We have characterized by WGS all ESC-resistant $E$. coli isolated from retail chicken in Norway in 2012, 2014, and 2016 obtained through the NORM-VET monitoring program. This enabled in-depth characterization of the population dynamics among ESC-resistant isolates over a prolonged time period. As mentioned earlier NORMVET is governed by the legislation for surveillance of $A M R$, and the sampling was therefore performed 
Table 1 Overview of genetic characteristics, including virulence and AMR genes, for 18 extended-spectrum cephalosporin-resistant Escherichia coli isolates included in the phenotypic characterization

\begin{tabular}{|c|c|c|c|c|c|c|}
\hline ID & Year & ST & $\begin{array}{l}\text { Phylo- } \\
\text { group }\end{array}$ & Serotype & AMR genes & UPEC associated virulence genes \\
\hline $\begin{array}{l}2012-01- \\
1292\end{array}$ & 2012 & 38 & $\mathrm{D}$ & $\mathrm{O} 7 \mathrm{H} 18$ & $b / a_{\mathrm{CMY}-2}$ & $\begin{array}{l}\text { fimA-l, iucA-D, iutA, chuA, chuS-Y, entA-F, entS, fepA-D, fepG, iroN, kpsM, iss, } \\
\text { cma, }\end{array}$ \\
\hline $\begin{array}{l}2012-01- \\
1295\end{array}$ & 2012 & 38 & $\mathrm{D}$ & $\mathrm{O}: \mathrm{H} 18$ & $b l a_{\mathrm{CMY}-2}$ & $\begin{array}{l}\text { fimA-l, iucA-D, iutA, chuA, chuS-Y, entA-F, entS, fepA-D, fepG, iroN, kpsM, iss, iha, } \\
\text { cma, }\end{array}$ \\
\hline $\begin{array}{l}2012-01- \\
2798\end{array}$ & 2012 & 3249 & A & $\mathrm{O}: \mathrm{H9}$ & bla $a_{\mathrm{CMY}-2}$ sul1 & fim $C-1$, ent $A$, ent $C$, entE- $F$, entS, fep $C-D$, fep $G$, iss, ast $A$, celB, cma \\
\hline $\begin{array}{l}2012-01- \\
3586\end{array}$ & 2012 & 131 & B2 & $\mathrm{O} 25: \mathrm{H} 4$ & bla $a_{C M Y-2}$ & $\begin{array}{l}\text { fimB-l, iucA-D, iutA, chuA, chuS-Y, entA-C, entE-F, entS, fepA-D, fepG, iro N, tsh, } \\
\text { kps } M \text {, iss, fyuA, iha, usp, celB, mchB, mchC, tsh }\end{array}$ \\
\hline $\begin{array}{l}2012- \\
01-707\end{array}$ & 2012 & 38 & $\mathrm{D}$ & $\mathrm{O} 7 \mathrm{H} 18$ & bla $a_{\mathrm{CMY}-2}$, sul2 & $\begin{array}{l}\text { papB, papl, fimA-l, iucB-D, iutA, chuA, chuS-Y, entA-F, entS, fepA-D, fepG, iroN, } \\
\text { kpsM, iss, iha, cma }\end{array}$ \\
\hline $\begin{array}{l}2012- \\
01-771\end{array}$ & 2012 & 69 & $\mathrm{D}$ & $\begin{array}{l}\mathrm{O} 17 / \mathrm{O} 44, \mathrm{O} 17 / \\
\mathrm{O} 77: \mathrm{H} 18\end{array}$ & 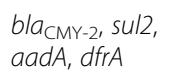 & $\begin{array}{l}\text { fimB-D, fimF-l, iucA-D, iutA, chuS, chuU-Y, entA-C, entE- } F \text {, entS, fepA-D, fepG, iss, } \\
\text { astA, cma }\end{array}$ \\
\hline $\begin{array}{l}2014-01- \\
1336\end{array}$ & 2014 & 1594 & A & $\mathrm{O} 21: \mathrm{H} 4$ & $\begin{array}{l}\text { bla } \\
\text { bla } a_{\mathrm{TEM} 1}\end{array}$ & fimA-I, iucA-D, iutA, entA-C, entE-F, entS, fepA-D, fepG, kps $M$, astA, celB \\
\hline $\begin{array}{l}2014-01- \\
3678\end{array}$ & 2014 & 117 & $\mathrm{D}$ & $\mathrm{O} 24: \mathrm{H} 4$ & $\begin{array}{l}\text { bla } \\
\text { adAY-2, sult, }\end{array}$ & $\begin{array}{l}\text { papB-papK, sfaX, fimB-l, iucB-D, iutA, chuA, chuS-Y, entA-C, entE-F, entS, fepA-D, } \\
\text { fepG, iroN, pic, vat, ireA, fyuA, mcmA }\end{array}$ \\
\hline $\begin{array}{l}2014-01- \\
3680\end{array}$ & 2014 & 1158 & $\mathrm{D}$ & $\begin{array}{l}\mathrm{O} 17 / \mathrm{O} 44, \mathrm{O} 17 / \\
\mathrm{O} 77: \mathrm{H} 34\end{array}$ & $b / a_{\mathrm{CMY}-2}$ & $\begin{array}{l}\text { fimA-C, fimE-I, iucA-D, iutA, chuA, chuS-Y, entA-C, entE-F, entS, fepA-D, fepG, } \\
\operatorname{kps} M \text {, iss, iha }\end{array}$ \\
\hline $\begin{array}{l}2014-01- \\
4267\end{array}$ & 2014 & 191 & A & O150:H20 & $b / a_{\mathrm{CMY}-2}$ & fimA-I, entA-C, entE-F, entS, fepA-D, fepG, iha, mchB, mchC, mchF \\
\hline $\begin{array}{l}2014-01- \\
4991\end{array}$ & 2014 & 57 & $\mathrm{D}$ & ONT:H18 & $b l a_{\mathrm{CMY}-2}$ & fimA-C, fimE-I, chuA, chuS-Y, entA-C, entE-F, entS, fepA-D, fep G \\
\hline $\begin{array}{l}2014-01- \\
5104\end{array}$ & 2014 & 115 & $\mathrm{D}$ & O102:H6 & $b / a_{\mathrm{CMY}-2}$ & $\begin{array}{l}\text { fimA-l, iucB-D, iutA, chuV-Y, entA-F, entS, fepA-D, fepG, kpsM, iss, astA, cba, celB, } \\
\text { cma }\end{array}$ \\
\hline $\begin{array}{l}2014-01- \\
5656\end{array}$ & 2014 & 10 & A & O125ab:H4 & bla $a_{\mathrm{CMY}-2}$ & fimB-I, iucB-D, iutA, entA-C, entE- $F$, entS, fepA-D, fep G, iss, fyuA, ast $A$, iha \\
\hline $\begin{array}{l}2014-01- \\
7011\end{array}$ & 2014 & 1944 & $\mathrm{D}$ & O38:H39 & bla $a_{\mathrm{CMY}-2}$ & fimF-H, chuA, chuS-Y, entA-F, entS, fepA-D, fepG, iha, cma, mchB, mchC, mchF \\
\hline $\begin{array}{l}2014-01- \\
7037\end{array}$ & 2014 & 355 & B2 & $\mathrm{O} 2: 050 / \mathrm{O} 2: \mathrm{H} 5$ & bla $a_{\mathrm{CMY}-2}$ & $\begin{array}{l}\text { fimB-l, iucA-D, iutA, chuA, chus-Y, entA-C, entE-F, entS, fepA-D, fepG, kps } M \text {, iss, } \\
\text { fyuA, astA, iha, usp, cba, celB, cma }\end{array}$ \\
\hline $\begin{array}{l}2016- \\
22-220\end{array}$ & 2016 & 429 & B2 & O50/O2:H1 & $\begin{array}{l}\text { bla } \text { CMY-2, sult, }_{1} \\
\operatorname{aadA} \text {, aac, tetA }\end{array}$ & $\begin{array}{l}\text { fimA-I, iucB-D, iutA, chuA, chus-Y, entA-F, entS, fepA-D, fepG, iroN, kpsM, iss, fyuA, } \\
\text { usp, mchF }\end{array}$ \\
\hline $\begin{array}{l}2016- \\
22-832\end{array}$ & 2016 & 442 & B1 & O91:H21 & $b l a_{C M Y-2}, d f r A$ & fimB-I, iucB-D, iutA, entA-C, entE-F, entS, fepA-D, fepG, iroN, mchF \\
\hline $\begin{array}{l}2016-22- \\
1061\end{array}$ & 2016 & 2040 & A & O159:H20 & $b / a_{C M Y-2}$ & fimA-I, iucB-D, iutA, entA-F, entS, fepA-D, fepG, iroN, tsh, cma \\
\hline
\end{tabular}

following defined schemes designed to be representative for the entire population [21].

Since 2012 there has been a significant decrease in the occurrence of ESC-resistant E. coli in Norwegian retail chicken [40]. Newly published data showed that only $0.4 \%$ of samples were positive in 2018 [40]. Furthermore, semi-quantitative methods have revealed that in the vast majority of Norwegian retail chicken samples where ESC-resistant $E$. coli were detected, only very low levels of these bacteria were present $(\leq 0.2 \mathrm{cfu} / \mathrm{g})[19,41]$. This is consistent with recent trends reported from Denmark, Sweden, and the Netherlands, where a decrease in the number of ESC-resistant isolates has also been described over the last decade [42-44]. In 2014, the Norwegian poultry industry initiated an action plan against antimicrobial resistant bacteria in broiler production [22]. The sum of measures taken by the industry, both nationally and internationally, has likely contributed to improve the situation.

Although the occurrence of ESC-resistant E. coli in Norwegian retail chicken decreased during the five-year study period, the relatively large variation in STs indicates that there are annual fluctuations in the population of ESC-resistant E. coli STs. This underlines the complex epidemiology of ESC-resistant E. coli, which has also been highlighted by others [45]. Understanding the epidemiology is further complicated by the occurrence of both vertical and horizontal dissemination of ESC- 


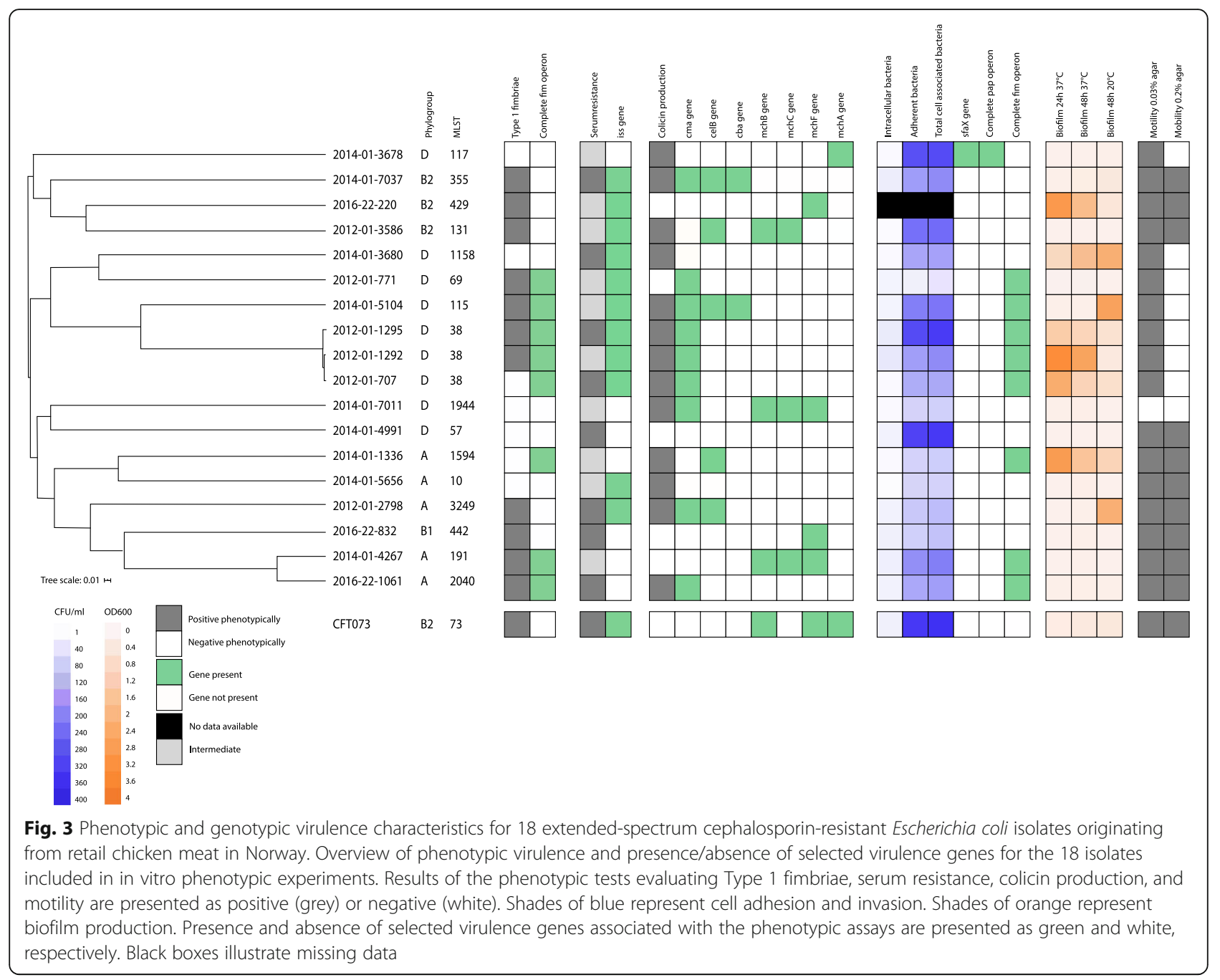

resistance. The vast majority of ESC-resistant E. coli included in this study were known to carry $b l a_{\mathrm{CMY}-2}$ on self-transferable IncK plasmids [46]. However, in the emerging ST2040, bla $a_{\mathrm{CMY}-2}$ was present on a nontransferable IncI1 plasmid (unpublished data). We have not investigated if virulence genes were located on plasmids or a possible co-location of AMR- and virulence genes. In order to do so, it is necessary to perform longread sequencing to enable reliable hybrid assemblies. This would enable us to consider the potential of dissemination and co-dissemination of AMR- and virulence determinants in the bacterial population.

Only two STs were present over all three years, namely ST10 and ST1594. However, only one or a limited number of isolates belonging to these STs were detected each year, indicating that they were not common in the ESCresistant E. coli population. The three major STs in our material, ST38, ST1158, and ST2040, have all been previously described to occur in the broiler production in Europe [47-49]. This observation intrigues us to claim that certain successful ESC-resistant E. coli STs disseminate widely in the European broiler production, but further comparisons of sequence- and epidemiological data are warranted to confirm this hypothesis.

Five of the $19 \mathrm{E}$. coli STs identified among our isolates (ST131, ST117, ST38, ST10, and ST69) are included in the "top 20 ExPEC ST"-list published in a meta-analysis [50]. This included 217 studies that performed MLST or whole-genome sequencing to genotype E. coli recovered from extraintestinal infections or the gut. Our results from analyses of virulence associated genes and in vitro virulence assays revealed a large variation in the estimated virulence potential among the different STs including those that previously have been classified as ExPEC. The high diversity of virulence-associated traits suggests that the uropathogenic potential of ESCresistant E. coli from poultry meat is isolate dependent and/or dependent on the sensitivity of the individual host. Based on data from the in vitro virulence assays, none of the isolates belonging to known ExPEC STs 


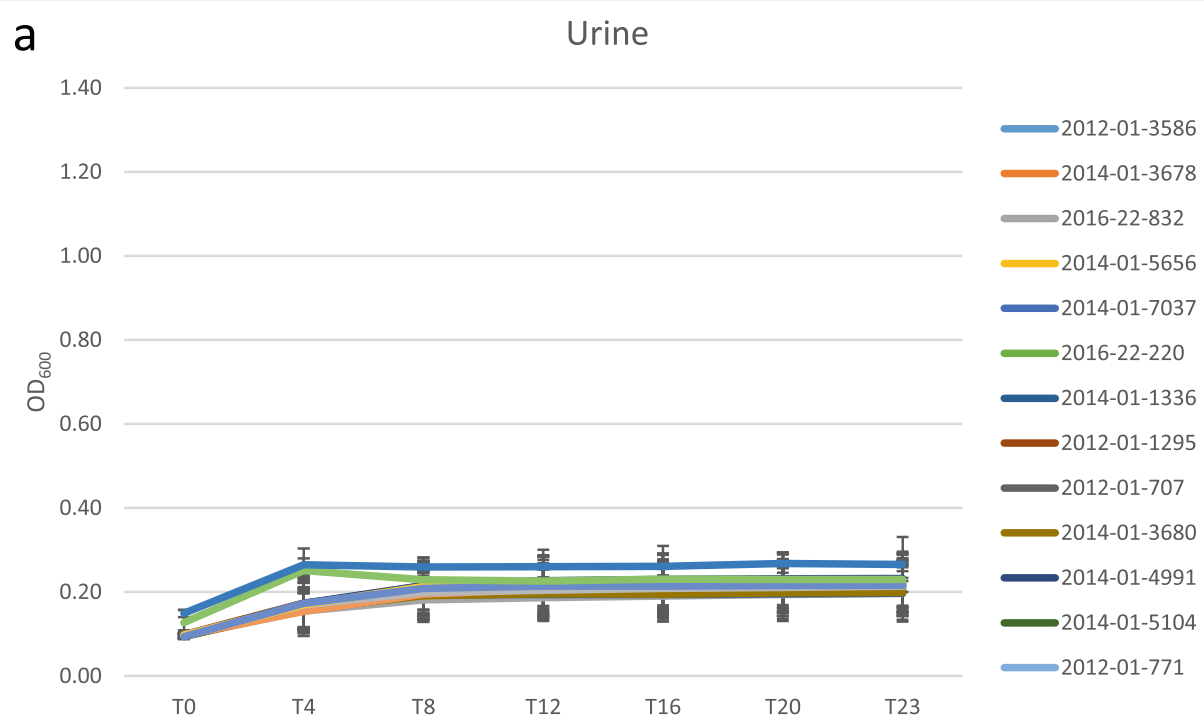

LB-broth

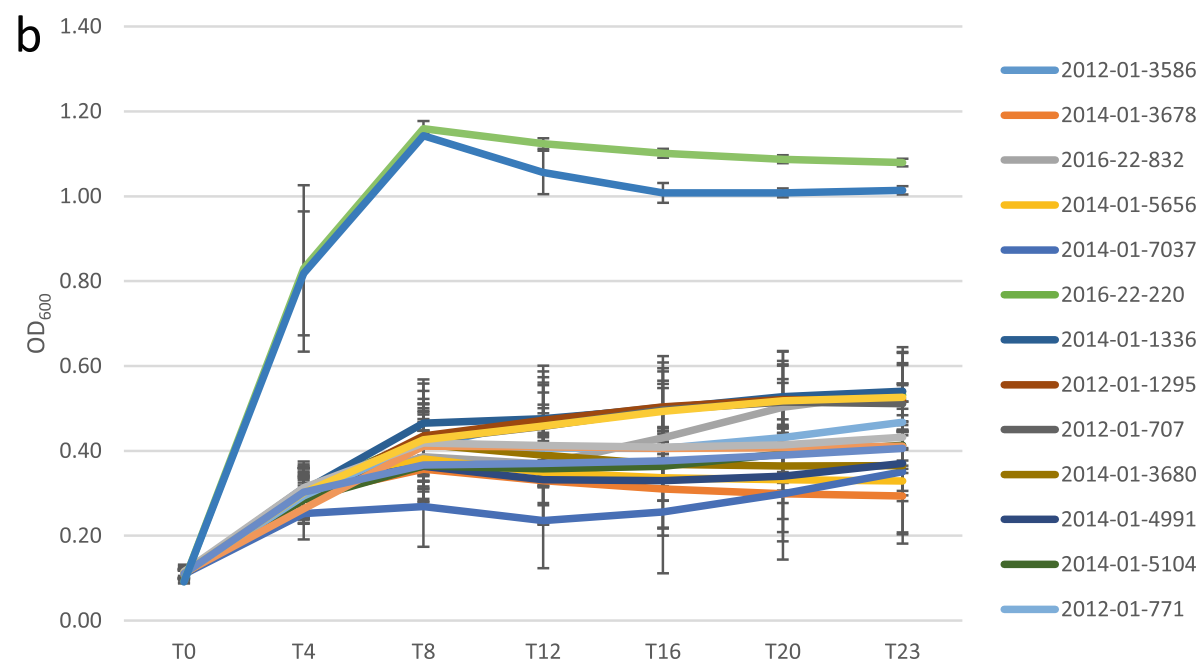

Fig. 4 Bacterial growth. The figure illustrates the growth of the $18 \mathrm{E}$. coli isolates included in the in vitro phenotypic studies in sterile filtered human urine (a) and LB broth (b). Growth in LB was included as a measure on optimal growth conditions and used as basis for comparison with growth in sterile filtered human urine. Growth curves were obtained from a Tecan plate reader in which the optical density was measured at 600 $\mathrm{nm}$ every ten minutes for $23 \mathrm{~h}$. Time is given in hours on the $\mathrm{x}$-axis, and the measured optical density on the $\mathrm{y}$-axis. The experiment was performed in triplicate, and the standard deviations are indicated by whiskers

appeared to have higher uropathogenic potential than isolates belonging to the other STs. However, host related factors have not been considered in this work, and thus may affect the clinical outcome in an infection.

An important prerequisite for developing a UTI is the ability of uropathogenic $E$. coli to adhere to and invade the uroepithelium, and thus colonize the mucosal epithelial surfaces in the urinary tract. Expression of type 1 fimbriae which mediate bacterial adhesion to mannose-containing structures on the uroepithelium is particularly associated with UTIs [51], and this feature was found in half of our selected isolates. Notably, several of the isolates were able to form functional type 1 fimbriae despite lacking a complete fim-operon. None of the isolates showed a high degree of invasiveness in Vero cells under the experimental conditions used, and this could indicate that long-term survival in the uroepithelium would be limited.

We evaluated biofilm formation, colicin production and ability to grow in urine, all of which may influence the ability of isolates to colonize the human urinary tract $[52,53]$. All isolates were able to grow in human urine, which may be a predictor of the colonization ability of 
uropathogens [54]. This is consistent with growth of $E$. coli CFT073 performed in urine by others $[55,56]$.

One of the first steps of colonization is the establishment of biofilm, which provides protection from the shear forces of passing urine in the urinary tract. In addition, the forming of biofilm will also provide advantages in avoiding the immune system and giving increased protection from antimicrobials [57]. The ability of the isolates to form biofilm in Luria-Bertani (LB) broth without $\mathrm{NaCl}$ was tested at two different temperatures, and at two different time points. Biofilm formation is highly dependent on environmental conditions and the access to nutrients. Half of the tested isolates were able to form biofilm and most isolates of those that were positive formed more biofilm at $37^{\circ} \mathrm{C}$ compared to $20^{\circ} \mathrm{C}$, possibly indicating ability to form biofilm in the human body. Previous reports have indicated that uropathogenic bacteria within biofilms or in biofilm-like communities may promote virulence under certain growth conditions, for example by creating intracellular pod-like bulges inside of the bladder epithelial cells $[58,59]$. This is considered important especially for recurrent UTIs, where the intracellular bacterial communities (IBC) facilitate persistence in the urinary epithelium $[58,59]$. Our study provided limited experimental conditions, where the ability to form IBCs was not studied. Further studies of the ability of ESC-resistant E. coli to form biofilm on human urinary tract epithelium are needed to evaluate their uropathogenic potential. The production of specific enzymes and toxins, for example colicins, can provide beneficial colonization conditions as it limits competition from other bacteria [52]. As most of our isolates produced colicins, we can assume that these isolates possess competitive advantages over other $E$. coli isolates in the intestines.

Serum resistance is a key virulence trait of isolates that cause urosepsis and all isolates tested were serum resistant. Urosepsis is a serious complication in UTIs that requires immediate medical care to avoid a possible lifethreatening situation [60]. Furthermore, if an UTI is caused by an UPEC isolate resistant to clinically relevant antimicrobials, the treatment could be complicated, prolonged and costly [61, 62].

Isolate 2016-22-1061 (ST2040) stood out as the isolate which expressed the most UPEC-associated virulence factors (type 1-fimbriae, production of colicins, survival in human serum, and the fastest growth in urine). Interestingly, this isolate belongs to phylogroup $\mathrm{A}$, which is rarely described to cause extraintestinal infections. Nevertheless, due to its estimated pathogenicity and recent emergence as described above, attention should be paid to this ST in future surveillance.

Isolate 2012-01-3586 belonged to ST131, serotype O25:H4 and phylogroup B2, which is known to be a notorious ExPEC ST and is considered a high-risk clone
$[63,64]$. Surprisingly, this isolate appeared have a lower virulence potential than expected; it produced colicin, expressed the type 1-fimbriae and adhered to eukaryotic cells, but it was among the isolates that expressed the lowest serum resistance. It did not invade Vero cells, and was a weaker biofilm producer compared to all isolates tested. Furthermore, none of the genes encoding toxins commonly produced by pathogenic ST131 isolates, namely pic, vat, sat, hlyA/D, ast $A, c d t B$, and $c n f 1$ $[65,66]$ were present in the genome of this isolate. We detected the fimH38 allele in isolate 2012-01-3586, while the global high-risk ST131 clone has been associated with the fimH30 allele [63, 67]. Thus, it is possible that this isolate belongs to a sub-group with lower pathogenic potential compared with the previously described ST131 ExPEC clone.

The lack of direct correlation between the observed genotypes and phenotypes in our experiments complicates interpretation of the results. Many of the traits that we investigated have complex genetic backgrounds, and several genes may give rise to the same phenotype. For example; isolate 2014-01-4991 (ST57) carried incomplete fim- and pap operons, and the sfaX gene was absent but still showed a high degree of cell adhesion in the phenotypic testing. This genotype to phenotype divergence illustrates the importance of performing in vitro virulence tests in order to assess the possible pathogenic potential of isolates rather than relying solely on comparative genomics $[68,69]$. Furthermore, the study of virulence associated traits was limited to only 18 isolates, but discrepancy observed between genotype and phenotype indicates that there could be differences in pathogenic potential within the same ST. For comparison of phenotypic characteristics of relevance for pathogenicity, we used E. coli CFT073 as a positive control strain in all our in vitro experiments. This strain was originally isolated from the blood of a woman with acute pyelonephritis and is regarded as an UPEC prototype [70]. However, none of the isolates that we investigated had an identical phenotypic profile to that of $E$. coli CFT073 (Fig. 3).

The plasmid mediated AmpC beta-lactamase encoding gene $b l a_{\mathrm{CMY}-2}$ has played a major role in conferring ESC-resistance in the Norwegian E. coli isolates, while genetic linkages to genes encoding resistance to other antimicrobial classes have not been prominent $[46,71]$. Previous studies of the phenotypical resistance patterns of these isolates have confirmed that the occurrence of co-resistance to other antimicrobials is limited [41, 71, 72]. In this study we focused on ESC-resistant E. coli. However, AMR and virulence genes are not necessarily linked, and it is possible that susceptible $E$. coli of broiler origin may have a different virulence potential than the ESC-resistant isolates investigated here. Several studies 
have suggested that food products, especially chicken meat, are an important source of ESC-resistant ExPEC $[31,36]$. On the other hand, other more recent studies have reported a limited contribution of chicken meat to the overall occurrence of ESC-resistant E. coli in humans [73-76]. By revisiting previously analyzed materials using WGS, de Been et al. failed to provide any evidence for recent clonal transmission of ESC-resistant E. coli strains from poultry to humans [77]. All these studies were performed in countries where the occurrence of ESC-resistant E. coli in poultry and/or chicken meat is higher than in Norway. The occurrence of ESCresistance among clinical UPEC isolates in Norway is considered very low, only $3.4 \%$ in 2018 [40]. However, results from one Norwegian study indicated that clonal transfer of ESC-resistant E. coli from chicken meat to humans may occur, and that these bacteria could be a source of ESC-resistance plasmids that could be transferred to bacteria residing in the human gut microbiota [78]. However, only a limited number of isolates were included in the Norwegian study, and the presence of virulence factors known to be associated with UTIs was not in focus.

One strength of our study is that all ESC-resistant $E$. coli isolated from retail chicken in Norway in 2012, 2014, and 2016 were characterized in depth using cgMLST and that acquired AMR genes and virulence genes were investigated. As well as providing an overview of the population structure, these data also demonstrate the occurrence or absence of genes that encode virulence factors of possible relevance regarding pathogenic potential.

\section{Conclusion}

Our study showed a fluctuation in the ST composition of ESC-resistant E. coli isolated from retail chicken meat in 2012, 2014, and 2016. Five of the STs present have previously been associated with ExPEC. However, results from the in vitro virulence assays did not indicate that our isolates from these STs had a higher pathogenic potential than isolates from other STs. These observations suggest that the estimated pathogenic potential of ESCresistant $E$. coli from poultry meat is highly dependent on the individual isolate. In conclusion, our results indicate that the uropathogenic potential of ESC-resistant $E$. coli from the Norwegian poultry reservoir is limited. It is reasonable to assume that the risk of being exposed to ESC-resistant E. coli with pathogenic potential through handling and consumption of chicken meat in Norway is low. However, we have also shown that the population structure of the ESC-resistant E. coli is dynamic and the genetic diversity of the fluctuating STs is considerable. It is therefore important to maintain monitoring programs and the implementation of preventive measures to hinder the emergence of AMR and potential pathogenic variants in the Norwegian broiler production.

\section{Materials and methods \\ Bacterial isolates}

All ESC-resistant E. coli isolated from domestically produced retail chicken meat in the NORM-VET program in $2012(n=66), 2014(n=58)$, and $2016(n=17)$ were included in the study (total $n=141$ ). All isolates were known to carry the $b l a_{\mathrm{CMY}-2}$ gene encoding ESC resistance $[19,41,72]$. Year of isolation, phylogroup, serotype, and AMR profile of the 18 isolates selected for in vitro virulence characterization are described in Table 1. E. coli CFT073 [79], a known UPEC strain, was also analyzed for comparison in the in vitro experiments.

\section{DNA extraction}

Total genomic DNA was extracted using the DSP DNA Mini Kit (Qiagen, Hilden, Germany) and the QIAsymphony automated extractor (Qiagen), or manually either using the QIAmp DNA Mini kit or the Qiagen Blood and Tissue kit (Qiagen). DNA concentration was determined on a Qubit ${ }^{\text {tix }}$ fluorometer (ThermoFischer Scientific, Waltham,) using the Qubit ${ }^{\text {tw }}$ dsDNA BroadRange assay kit (ThermoFischer Scientific). DNA purity was measured on a Nanodrop 2000 spectrophotometer (ThermoFischer Scientific).

\section{Whole genome sequencing}

Samples were prepared with either the Nextera XT or Nextera Flex library preparation kit (Illumina, San Diego, CA, USA). Whole genome sequencing was performed on an Illumina HiSeq X $(n=12)$ or Illumina NextSeq $500(n=107)$, resulting in $150 \mathrm{bp}$ paired-end reads, or on a HiSeq 2500 using rapid mode $(n=9)$, resulting in 250 bp paired-end reads. In addition, sequence data for 13 isolates (five from 2012 and eight from 2014) had been sequenced previously $[46,78]$, and raw reads were available for inclusion in the present study. An overview of which isolates were sequenced on the different platforms is provided in the Supplementary material (Table S1).

\section{Bioinformatics}

Initial quality control and assembly of samples was done using the Bifrost pipeline [80]. Briefly, quality control of the paired end reads was done using the FastQC tool (https://www.bioinformatics.babraham.ac.uk/projects/ fastqc/) and the results were merged using MultiQC [81]. Further, PhiX was removed by BBDuk (https:// sourceforge.net/projects/bbmap/), and sequences were trimmed with Trimmomatic [82]. Assembly was done using SPAdes [83], polished using Pilon [84], and the quality of the assemblies evaluated with QUAST [85]. 
Subsequently, the Bifrost pipeline for identification of specific genes such as MLST, AMR genes and virulence genes were used [86] In detail, the ARIBA (Antimicrobial Resistance Identification By Assembly) software [87] was used to determine multilocus sequence type (MLST) according to the Achtman scheme [88]. The presence of acquired resistance genes as well as virulence genes was determined using the ResFinder [89] and VirulenceFinder [90] and vfdb_core [91] databases, respectively. The analyses were performed in September 2019 and the updated databases were used. The E. coli serotypes were determined using SerotypeFinder [92].

Results from ARIBA were summarized using VAMP IR- Virulence, AMR, MLST and Plasmid analysis in $\mathrm{R}$ (https://github.com/hkaspersen/VAMPIR, commitid 54d687a) in $R$ version 3.5.2 [93].

All isolates were subjected to cgMLST analysis, including 2360 genes, in order to investigate the genetic relationship between isolates. This was done using the cgMLST scheme available from Enterobase (https:// enterobase.warwick.ac.uk/) in the chewBBACA suite [94]. The cgMLST tree was visualized using the ggtree package [95] in $R$ version 3.5.2 [93]. Sequence data is available at European Nucleotide Archive (ENA). Accesion numbers are given in Table 2.

\section{In vitro virulence expression}

Results from the genetic analysis and in vitro testing were summarized and visualized using iTOL (http:// itol.embl.de) [96], and are presented in Fig. 3.

Expression of type 1 fimbriae The ability to express a D-mannose-binding phenotype, characteristic for functional Type 1 fimbriae, was assayed by the ability to agglutinate yeast cells (Saccharomyces cerevisiae) [97]. Each isolate was inoculated into LB broth and incubated over night at $37^{\circ} \mathrm{C}$. One $\mathrm{ml}$ of overnight culture was centrifuged ( $3000 \mathrm{x} \mathrm{g}, 5 \mathrm{~min}$ ) and the pellet resuspended in $100 \mu \mathrm{l} \mathrm{PBS}$. Ten $\mu \mathrm{l}$ of the bacterial suspension was mixed with $10 \mu \mathrm{l}$ yeast cells $(5 \mathrm{mg} / \mathrm{ml}$, resuspended in PBS) with and without $1 \% \mathrm{D}$-mannose solution on a microscopy slide, and agglutination observed visually. Suspension containing $1 \%$ D-mannose was considered a negative control.

Table 2 Accession numbers for sequence data at European Nucleotide Archive (ENA)

\begin{tabular}{lllll}
\hline Group & Read length & Setsize & N & Project accession \\
\hline Nextseq & 150 & 2 & 107 & PRJEB40941 \\
HiseqX & 150 & 2 & 12 & PRJEB40952 \\
Hiseq2500 & 100 & 2 & 13 & PRJEB40969 \\
Hiseq2500rapid & 250 & 4 & 9 & PRJEB41003 \\
\hline
\end{tabular}

Motility test One colony from a fresh blood agar plate of each isolate was perpendicularly inoculated into a tube containing $5 \mathrm{ml}$ semi-solid LB agar, at concentrations of $0.03,0.2$, and $0.7 \%$ agar, and incubated for $24 \mathrm{~h}$ at $37^{\circ} \mathrm{C}$ [98]. Motile bacteria appeared as a "cloud" of bacterial growth in the agar around the stab-line.

Biofilm production Biofilm production was evaluated as described by Stromberg et al., with minor modifications [99]. Briefly, overnight cultures in LB broth were diluted 1:200 in $\mathrm{LB}$ without $\mathrm{NaCl}$, and $200 \mu$ ldded to a 96-well microtiter plate (Greiner, Sigma-Aldrich, Germany). Wells containing uninoculated media were used as negative controls. The plates were incubated at $37^{\circ} \mathrm{C}$ for $24 \mathrm{~h}$ and at $20^{\circ} \mathrm{C}$ for $48 \mathrm{~h}$. After incubation, the plates were washed three times with PBS to remove planktonic cells. Adhered bacteria were stained with $0.1 \%$ crystal violet for $15 \mathrm{~min}$, followed by washing three times with PBS. Thereafter, $200 \mu \mathrm{l}$ ethanol was added to each well and $\mathrm{OD}_{600}$ was measured using Infinite M200 plate reader (Tecan, Männedorf, Switzerland). Biofilm formation was considered when the $\mathrm{OD}_{600}$ was at least three times greater than that of the negative control [99].

Bacterial growth Overnight cultures of each isolate were diluted 1:1000 in fresh LB broth. Thereafter, $200 \mu \mathrm{l}$ of each isolate was transferred to a 96-well microtiter plate (Greiner, Sigma-Aldrich, Germany) and incubated at $37^{\circ} \mathrm{C}$ in Infinite M200 plate reader (Tecan). OD 600 was measured every $10 \mathrm{~min}$ for $24 \mathrm{~h}$. The experiment was repeated three times for each isolate.

In addition, bacterial growth was tested in sterilefiltered human urine $(\mathrm{pH}=6.5)$ with the same protocol as for LB. Urine was collected from healthy female volunteers with no history of UTI or antibiotic use in the previous two months.

Serum resistance In order to investigate resistance to human serum, $250 \mu \mathrm{l}$ of the overnight cultures were added to $750 \mu \mathrm{l} 20 \%$ human serum (Sigma-Merck) (HS, diluted in PBS) or heat-inactivated serum (HIS, control for comparison). Serum was inactivated by incubating in a water bath at $56^{\circ} \mathrm{C}$ for $60 \mathrm{~min}$. The mixtures were incubated at room-temperature, and samples were taken every hour for three hours. Samples were serially diluted and plated on LB agar plates. The plates were incubated for $24 \mathrm{~h}$ at $37^{\circ} \mathrm{C}$ and colonies counted. The colonies from HS samples were calculated as a percentage of the HIS samples. The results were categorized as follows: $<1 \%=$ serum sensitive, $>90 \%=$ serum resistant, and all other results were considered as intermediate [100]. 
Adhesion to and invasion of eukaryotic cells Adhesion to, and invasion of, cells was tested in Vero cells (Vero C1008, ECACC, Item number 85020206) grown at $37^{\circ} \mathrm{C}$ [101]. The cells were grown to $80 \%$ confluence, and $200 \mu \mathrm{l}$ of cells in fresh minimal essential medium (DMEM (GibcoTM 11,568,876)) with 10\% Fetal Bovine Serum (GibcoTM 10,270,106) and $1 \mathrm{ml}$ penicillin/streptomycin solution (GibcoTM, 15,140,122, containing 10,000 units $/ \mathrm{ml}$ penicillin and $10,000 \mu \mathrm{g} / \mathrm{ml}$ streptomycin) added to $100 \mathrm{ml}$ DMEM was transferred to a microtiter plate (Greiner, Sigma-Aldrich, Germany). This was done in duplicate, at a concentration of approximately $5 * 10^{4}$ cells $/ \mathrm{ml}$ (counted in Countess (Thermo Scientific,), and the cells grown to confluence. Overnight cultures of bacteria were diluted 1:100 in fresh $\mathrm{LB}$ broth to $\mathrm{OD}_{600}=0.1$. One $\mathrm{ml}$ was centrifuged at $500 \mathrm{x} \mathrm{g}$ for $5 \mathrm{~min}$ and the pellet was resuspended in $500 \mu \mathrm{l}$ fresh DMEM cell-medium without antibiotics. The bacterial suspension was diluted 1:100 in DMEM cell-medium without antibiotics and $50 \mu \mathrm{l}$ was added to the confluent Vero cells with fresh cell medium, equivalent to approximately 30 bacteria per cell (MOI 30:1). The plates were centrifuged at $100 \mathrm{x} g$ for $2 \mathrm{~min}$ to increase contact between bacteria and cells, and incubated for two hours at $37^{\circ} \mathrm{C}$.

To assess adhesion to cells, the cells were washed three times with PBS to remove non-adherent bacteria and lysed with $30 \mu \mathrm{l} 1 \%$ Triton X for $10 \mathrm{~min}$. The lysates were serially diluted in PBS and plated on LB agar. To assess bacterial invasion, $200 \mu \mathrm{l}$ of fresh medium with antibiotics $(0.1 \mathrm{mg} / \mathrm{ml}$ gentamicin and $20 \mathrm{mg} / \mathrm{ml}$ nalidixic acid) was added to the cells before incubation at $37^{\circ} \mathrm{C}$ for two hours to kill adherent bacteria. The cells were lysed and plated as described for the adhesion assay.

Colicin production Colicin production was investigated as described previously [102]. Briefly, $100 \mu$ l overnight culture of $E$. coli DH5 $\alpha$ was spread onto LB agar plates and left to dry for approximately $10 \mathrm{~min}$ at room temperature. One $\mathrm{ml}$ overnight culture of the respective isolates was centrifuged at $13000 \mathrm{x}$ g for $10 \mathrm{~min}$ and the supernatants sterile filtered through a $0.22-\mu \mathrm{m}$ Minisart ${ }^{\circ}$ syringe filter (Sartorius Stedim Biotech $\mathrm{GmbH}$, Germany). Ten $\mu \mathrm{l}$ of the filtrate was spot inoculated on the dried LB agar plates with E. coli DH5 $\alpha$ and incubated at $37^{\circ} \mathrm{C}$ for $24 \mathrm{~h}$. Production of colicin was determined by the presence of an inhibition zone around the place of inoculation.

Statistical analysis All assays were performed in three parallels for each isolate, and each experiment was repeated three times. Standard deviations (SDs) for quantitative data were calculated (supplementary material).

\section{Supplementary Information}

The online version contains supplementary material available at https://doi. org/10.1186/s12866-021-02160-y

\section{Additional file 1.}

Additional file 2.

\section{Acknowledgements}

The sequencing service was provided by the Norwegian Sequencing Centre (www.sequencing.uio.no), a national technology platform hosted by the University of Oslo and supported by the "Functional Genomics" and "Infrastructure" programs of the Research Council of Norway and the Southeastern Regional Health Authorities.

The bioinformatics work was performed on the Abel Cluster, owned by the University of Oslo and Uninett/Sigma2, and operated by the Department for Research Computing at USIT, the University of Oslo IT-department. http:// www.hpc.uio.no/.

\section{Authors' contributions}

All authors have contributed to the ideas and concepts, the study design and manuscript preparation. MLB and SSM performed the experiments and the genomics, wrote the main manuscript and prepared Figs. CS assisted the bioinformatics. ILW assisted laboratory experiments. MLB, SSM, ILW, CS, MS, YW reviewed the manuscript. All authors of the manuscript have read and agreed to its content and are accountable for all aspects of the accuracy and integrity of the manuscript.

\section{Funding}

This study was funded by The Research Council of Norway. (Grant no: 250212.) Founders were not involved in the design, collection of materials, analysis of data or writing the manuscript.

\section{Availability of data and materials}

The datasets used and/or analyzed during the current study are available from the corresponding author on reasonable request. Sequence data is available at European Nucleotide Archive (ENA). Accession numbers are given in Table 2.

\section{Declarations}

Ethics approval and consent to participate

Not applicable. Urine samples were provided by the authors themselves; no ethical parameters are required.

\section{Consent for publication}

Not applicable.

\section{Competing interests}

The authors have no competing interest to declare.

\section{Author details}

${ }^{1}$ Department of Paraclinical Sciences, Faculty of Veterinary Medicine, Norwegian University of Life Sciences, Oslo, Norway. ${ }^{2}$ Section for Food safety and Animal Health Research, Department of Animal Health and Food Safety, Norwegian Veterinary Institute, Oslo, Norway.

Received: 28 September 2020 Accepted: 17 March 2021

Published online: 29 March 2021

\section{References}

1. Kaper JB, Nataro JP, Mobley HLT. Pathogenic Escherichia coli. Nat Rev Microbiol. 2004;2(2):123-40 https://doi.org/10.1038/nrmicro818.

2. Vila J, Saez-Lopez E, Johnson JR, Romling U, Dobrindt U, Canton R, et al. Escherichia coli: an old friend with new tidings. FEMS Microbiol Rev. 2016; 40(4):437-63 https://doi.org/10.1093/femsre/fuw005.

3. Johnson JR, Russo TA. Molecular epidemiology of extraintestinal pathogenic (uropathogenic) Escherichia coli. Int J Med Microbiol. 2005;295(6-7):383-404 https://doi.org/10.1016/j.jimm.2005.07.005.

4. Dobrindt U. (Patho-)genomics of Escherichia coli. Int J Med Microbiol. 2005; 295(6-7):357-71 https://doi.org/10.1016/j.jijmm.2005.07.009. 
5. Manges AR, Johnson JR. Reservoirs of Extraintestinal Pathogenic Escherichia coli. Microbiol Spectr. 2015;3(5) https://doi.org/10.1128/microbiolspec.UTI0006-2012. PMID: 26542041.

6. Ibarz Pavón AB, Maiden MCJ. Multilocus sequence typing. Methods Mol Biol. 2009;551:129-40 https://doi.org/10.1007/978-1-60327-999-4_11.

7. Flores-Mireles AL, Walker JN, Caparon M, Hultgren SJ. Urinary tract infections: epidemiology, mechanisms of infection and treatment options. Nat Rev Microbiol. 2015;13(5):269-84 https://doi.org/10.1038/nrmicro3432.

8. Terlizzi ME, Gribaudo G, Maffei ME. UroPathogenic Escherichia coli (UPEC) Infections: Virulence Factors, Bladder Responses, Antibiotic, and Nonantibiotic Antimicrobial Strategies. Front Microbiol. 2017;8:1566.

9. Hooton TM. Clinical practice. Uncomplicated urinary tract infection. N Engl J Med. 2012;366(11):1028-37 https://doi.org/10.1056/NEJMcp1104429.

10. George DB, Manges AR. A systematic review of outbreak and non-outbreak studies of extraintestinal pathogenic Escherichia coli causing communityacquired infections. Epidemiol Infect. 2010;138(12):1679-90 https://doi.org/1 $0.1017 /$ S0950268810001639.

11. Sarowska J, Futoma-Koloch B, Jama-Kmiecik A, Frej-Madrzak M, Ksiazczyk M, Bugla-Ploskonska $\mathrm{G}$, et al. Virulence factors, prevalence and potential transmission of extraintestinal pathogenic Escherichia coli isolated from different sources: recent reports. Gut Pathog. 2019;11(1):10 https://doi.org/1 0.1186/s13099-019-0290-0.

12. Schmiemann G, Kniehl E, Gebhardt K, Matejczyk MM, Hummers-Pradier E. The diagnosis of urinary tract infection: a systematic review. Deutsches Arzteblatt international. 2010;107(21):361-7 https://doi.org/10.3238/arztebl.2 010.0361 .

13. O'Neill J. Tackling drug-resistant infections globally: final report and recommendations; 2016.

14. EMEA. The Bacterial Challenge: time to react. Stockholm: European Centre for Disease Prevention and Control; 2009. Contract No.: EMEA/576176/2009

15. EFSA. The European Union summary report on antimicrobial resistance in zoonotic and indicator bacteria from humans, animals and food in 2015: Wiley; 2017. 2017/02/01. Report No.: 1831-4732 Contract No.: 2

16. EFSA. The European Union summary report on antimicrobial resistance in zoonotic and indicator bacteria from humans, animals and food in 2017: Wiley; 2019. 2019/02/01. Report No.: 1831-4732 Contract No.: 2

17. EFSA. The European Union summary report on antimicrobial resistance in zoonotic and indicator bacteria from humans, animals and food in 2016: Wiley; 2018. 2018/02/01. Report No.: 1831-4732 Contract No.: 2

18. European Food Safety A, European Centre for Disease P, Control. The European Union summary report on antimicrobial resistance in zoonotic and indicator bacteria from humans, animals and food in 2017. EFSA J. 2019;17(2):e05598.

19. NORM/NORM-VET. 2016 Usage of Antimicrobial Agents and Occurrence of Antimicrobial Resistance in Norway. Tromsø/Oslo; 2017. Report No.: ISSN 1502-2307 (print)/1890-9965 (electronic)

20. NORM/NORM-VET 2017. Usage of Antimicrobial Agents and Occurrence of Antimicrobial Resistance in Norway. Tromsø / Oslo; 2018. ISSN:1502-2307 (print) / 1890-9965 (electronic)

21. 2013/652/EU: Commission Implementing Decision of 12 November 2013 on the monitoring and reporting of antimicrobial resistance in zoonotic and commensal bacteria (notified under document C (2013) 7145) Text with EEA relevance, (2013).

22. Animalia. Fjørfenæringas handlingsplan mot resistente bakterier 2016. Available from: https://www.animalia.no/no/Dyr/antibiotikaresistens/fjorfena ringas-handlingsplan-mot-resistente-bakterier/.

23. Animalia. Actions to combat antimicrobial resistance works (Tiltak mot antibiotikaresistens virker; in Norwegian). 2017.

24. Animalia. Continued decrease in the occurrence of resistant bacteria in poultry (Fortsatt nedgang i forekomst av resistente bakterier hos fjørfe; in Norwegian) 2017.

25. Animalia. Status for the poultry industry action plan against resistant bacteria in 2016 (Status for fjørfenæringas handlingsplan mot resistante bakterier i 2016; in Norwegian) 2017.

26. Animalia. Action plan: No detection of ESBL in samples from imported poultry in 2017 (Handlingsplan: Ingen funn av ESBL i prøver fra fjørfeimporter i 2017; in Norwegian). 2018

27. Refsum T. Antimicrobial use in the Norwegian poultry production (Antibiotikabehandling i norsk fjørfeproduksjon; in Norwegian): Go'mørning; 2015.
28. NORM/NORM-VET. 2006 Usage of Antimicrobial Agents and Occurrence of Antimicrobial Resistance in Norway. Tromsø/Oslo; 2007. Report No.: ISSN: 1502-2307

29. NORM/NORM-VET. Usage of Antimicrobial Agents and Occurrence of Antimicrobial Resistance in Norway in 2018. Trømsø/Oslo; 2019. Report No.: 1502-2307 (print) / 1890-9965 (electronic)

30. Voets GM, Fluit AC, Scharringa J, Schapendonk C, van den Munckhof T, Leverstein-van Hall MA, et al. Identical plasmid AmpC beta-lactamase genes and plasmid types in E. coli isolates from patients and poultry meat in the Netherlands. Int J Food Microbiol. 2013;167(3):359-62 https://doi.org/10.101 6/j.ijfoodmicro.2013.10.001.

31. Vieira AR, Collignon P, Aarestrup FM, McEwen SA, Hendriksen RS, Hald T, et al. Association between antimicrobial resistance in Escherichia coli isolates from food animals and blood stream isolates from humans in Europe: an ecological study. Foodborne Pathog Dis. 2011;8(12):1295-301 https://doi. org/10.1089/fpd.2011.0950.

32. Kluytmans JA, Overdevest IT, Willemsen I, Kluytmans-van den Bergh MF, van der Zwaluw K, Heck M, et al. Extended-spectrum beta-lactamase-producing Escherichia coli from retail chicken meat and humans: comparison of strains, plasmids, resistance genes, and virulence factors. Clin Infect Dis. 2013;56(4):478-87 https://doi.org/10.1093/cid/cis929.

33. WHO. Antimicrobial resistance: Global report on surveillance 2014; 2014.

34. Johnson TJ, Wannemuehler $Y$, Johnson SJ, Stell AL, Doetkott C, Johnson JR, et al. Comparison of extraintestinal pathogenic Escherichia coli strains from human and avian sources reveals a mixed subset representing potential zoonotic pathogens. Appl Environ Microbiol. 2008;74(22):7043-50 https:// doi.org/10.1128/AEM.01395-08.

35. Jakobsen L, Hammerum AM, Frimodt-Møller N. Virulence of Escherichia coli B2 isolates from meat and animals in a murine model of ascending urinary tract infection (UTI): evidence that UTI is a zoonosis. J Clin Microbiol. 2010; 48(8):2978-80 https://doi.org/10.1128/JCM.00281-10.

36. Lazarus B, Paterson DL, Mollinger JL, Rogers BA. Do human extraintestinal Escherichia coli infections resistant to expanded-spectrum cephalosporins originate from food-producing animals? A systematic review. Clin Infect Dis. 2015;60(3):439-52 https://doi.org/10.1093/cid/ciu785.

37. Manges AR. Escherichia coli and urinary tract infections: the role of poultrymeat. Clin Microbiol Infect. 2016;22(2):122-9 https://doi.org/10.1016/j.cmi.2 015.11.010.

38. Vincent JL, Rello J, Marshall J, Silva E, Anzueto A, Martin CD, et al. International study of the prevalence and outcomes of infection in intensive care units. JAMA. 2009;302(21):2323-9 https://doi.org/10.1001/jama.2009.1 754.

39. VKM. Assessment of antimicrobial resistance in the food chains in Norway. In: Safety OotPomhotNSCfF, editor. Oslo, Norway; 2015.

40. NORM/NORM-VET. 2018 Usage of Antimicrobial Agents and Occurrence of Antimicrobial Resistance in Norway. Trømsø/Oslo; 2019. Report No.: 15022307 (print) / 1890-9965 (electronic)

41. NORM/NORM-VET. NORM/NORM-VET 2014. Usage of Antimicrobial Agents and Occurrence of Antimicrobial Resistance in Norway. Tromsø/Oslo; 2015. Report No.: ISSN: 1502-2307 (print)/1890-9965 (electronic)

42. DANMAP. 2018 - Use of antimicrobial agents and occurrence of antimicrobial resistance in bacteria from food animals, food and humans in Denmark. 2019.

43. Swedres-Svarm. 2018 - Consumption of antibiotics and occurrence of resistance in Sweden. 2019.

44. NethMap. Consumption of antimicrobial agents and antimicrobial resistance among medically important bacteria in the Netherlands in 2018. 2019.

45. Päivärinta M, Latvio S, Fredriksson-Ahomaa M, Heikinheimo A. Whole genome sequence analysis of antimicrobial resistance genes, multilocus sequence types and plasmid sequences in ESBL/AmpC Escherichia coli isolated from broiler caecum and meat. Int J Food Microbiol. 2020;315: 108361 https://doi.org/10.1016/j.ijfoodmicro.2019.108361.

46. Mo SS, Slettemeas JS, Berg ES, Norstrom M, Sunde M. Plasmid and host strain characteristics of Escherichia coli resistant to extended-Spectrum Cephalosporins in the Norwegian broiler production. PLoS One. 2016;11(4): e0154019 https://doi.org/10.1371/journal.pone.0154019.

47. Vogt D, Overesch G, Endimiani A, Collaud A, Thomann A, Perreten V. Occurrence and genetic characteristics of third-generation cephalosporinresistant Escherichia coli in Swiss retail meat. Microbial Drug Resist (Larchmont, NY). 2014;20(5):485-94. 
48. Pietsch M, Irrgang A, Roschanski N, Brenner Michael G, Hamprecht A, Rieber $\mathrm{H}$, et al. Whole genome analyses of CMY-2-producing Escherichia coli isolates from humans, animals and food in Germany. BMC Genomics. 2018; 19(1):601 https://doi.org/10.1186/s12864-018-4976-3.

49. Hansen KH, Bortolaia V, Nielsen CA, Nielsen JB, Schonning K, Agerso Y, et al. Host-specific patterns of genetic diversity among Incl1-Igamma and IncK plasmids encoding CMY-2 beta-lactamase in Escherichia coli isolates from humans, poultry meat, poultry, and dogs in Denmark. Appl Environ Microbiol. 2016;82(15):4705-14 https://doi.org/10.1128/AEM.00495-16.

50. Manges AR, Geum HM, Guo A, Edens TJ, Fibke CD, Pitout JDD. Global Extraintestinal Pathogenic Escherichia coli (ExPEC) Lineages. Clin Microbiol Rev. 2019;32(3):e00135-18 https://doi.org/10.1128/CMR.00135-18. PMID: 31189557; PMCID: PMC6589867.

51. Schwartz DJ, Kalas V, Pinkner JS, Chen SL, Spaulding CN, Dodson KW, et al. Positively selected FimH residues enhance virulence during urinary tract infection by altering FimH conformation. Proc Natl Acad Sci U S A. 2013; 110(39):15530-7 https://doi.org/10.1073/pnas.1315203110.

52. Majeed H, Gillor O, Kerr B, Riley MA. Competitive interactions in Escherichia coli populations: the role of bacteriocins. ISME J. 2011;5(1):71-81 https://doi. org/10.1038/ismej.2010.90.

53. Beloin C, Roux A, Ghigo JM. Escherichia coli biofilms. Curr Top Microbiol Immunol. 2008;322:249-89 https://doi.org/10.1007/978-3-540-75418-3_12.

54. Stamey TA, Mihara G. Observations on the growth of urethral and vaginal bacteria in sterile urine. J Urol. 1980;124(4):461-3 https://doi.org/10.1016/ S0022-5347(17)55496-8.

55. Forsyth VS, Armbruster CE, Smith SN, Pirani A, Springman AC, Walters MS, et al. Rapid Growth of Uropathogenic \&lt;em\&gt;Escherichia coli\&lt;/em\&gt; during Human Urinary Tract Infection. mBio. 2018;9(2):e00186-18.

56. Roos V, Ulett GC, Schembri MA, Klemm P. The asymptomatic bacteriuria Escherichia coli strain 83972 outcompetes uropathogenic E. coli strains in human urine. Infect Immun. 2006;74(1):615-24 https://doi.org/10.1128/IAI. 74.1.615-624.2006.

57. Eberly AR, Floyd KA, Beebout CJ, Colling SJ, Fitzgerald MJ, Stratton CW, et al. Biofilm Formation by Uropathogenic Escherichia coli Is Favored under Oxygen Conditions That Mimic the Bladder Environment. Int J Mol Sci. 2017;18(10):2077 https://doi.org/10.3390/ijms18102077. PMID: 28973965; PMCID: PMC5666759.

58. Anderson GG, Palermo JJ, Schilling JD, Roth R, Heuser J, Hultgren SJ. Intracellular bacterial biofilm-like pods in urinary tract infections. Science. 2003;301(5629):105-7 https://doi.org/10.1126/science.1084550.

59. Justice SS, Hung C, Theriot JA, Fletcher DA, Anderson GG, Footer MJ, et al. Differentiation and developmental pathways of uropathogenic Escherichia coli in urinary tract pathogenesis. Proc Natl Acad Sci U S A. 2004;101(5): 1333-8 https://doi.org/10.1073/pnas.0308125100.

60. Thornton HV, Hammond A, Hay AD. Urosepsis: a growing and preventable problem? Br J Gen Pract. 2018;68(675):493-4 https://doi.org/10.3399/bjgp1 8X699317.

61. Alam MF, Cohen D, Butler C, Dunstan F, Roberts Z, Hillier S, et al. The additional costs of antibiotics and re-consultations for antibiotic-resistant Escherichia coli urinary tract infections managed in general practice. Int J Antimicrob Agents. 2009;33(3):255-7 https://doi.org/10.1016/j.ijantimicag.2 008.08.027.

62. Nordstrom L, Liu CM, Price LB. Foodborne urinary tract infections: a new paradigm for antimicrobial-resistant foodborne illness. Front Microbiol. 2013; $4: 29$.

63. Nicolas-Chanoine MH, Bertrand X, Madec JY. Escherichia coli ST131, an intriguing clonal group. Clin Microbiol Rev. 2014;27(3):543-74 https://doi. org/10.1128/CMR.00125-13.

64. Mathers AJ, Peirano G, Pitout JD. The role of epidemic resistance plasmids and international high-risk clones in the spread of multidrug-resistant Enterobacteriaceae. Clin Microbiol Rev. 2015;28(3):565-91 https://doi.org/1 0.1128/CMR.00116-14

65. Blanco J, Mora A, Mamani R, Lopez C, Blanco M, Dahbi G, et al. Four main virotypes among extended-spectrum-beta-lactamase-producing isolates of Escherichia coli O25b:H4-B2-ST131: bacterial, epidemiological, and clinical characteristics. J Clin Microbiol. 2013;51(10):3358-67 https://doi.org/10.1128/ JCM.01555-13.

66. Johnson JR, Johnston B, Clabots C, Kuskowski MA, Castanheira M. Escherichia coli sequence type ST131 as the major cause of serious multidrug-Resistant E. coli infections in the United States. Clin Infect Dis. 2010;51(3):286-94 https://doi.org/10.1086/653932.
67. Price LB, Johnson JR, Aziz M, Clabots C, Johnston B, Tchesnokova V, et al. The epidemic of extended-spectrum-beta-lactamase-producing Escherichia coli ST131 is driven by a single highly pathogenic subclone, H30-Rx. mBio. 2013;4(6):e00377-13.

68. Benfey PN, Mitchell-Olds T. From genotype to phenotype: systems biology meets natural variation. Science (New York, NY). 2008;320(5875):495-7.

69. Bochner BR. New technologies to assess genotype-phenotype relationships. Nat Rev Genet. 2003;4(4):309-14 https://doi.org/10.1038/nrg1046.

70. Welch RA, Burland V, Plunkett G, Redford P, Roesch P, Rasko D, et al. Extensive mosaic structure revealed by the complete genome sequence of uropathogenic <em>Escherichia coli</em>. Proc Natl Acad Sci. 2002;99(26): 17020-4 https://doi.org/10.1073/pnas.252529799.

71. Mo SS, Norstrom M, Slettemeas JS, Lovland A, Urdahl AM, Sunde M. Emergence of AmpC-producing Escherichia coli in the broiler production chain in a country with a low antimicrobial usage profile. Vet Microbiol. 2014;171(3-4):315-20 https://doi.org/10.1016/j.vetmic.2014.02.002.

72. NORM/NORM-VET. NORM/NORM-VET 2012. Usage of Antimicrobial Agents and Occurrence of Antimicrobial Resistance in Norway. Tromsø/Oslo; 2013. Report No.: ISSN:1502-2307 (print) / 1890-9965 (electronic)

73. Mughini-Gras L, Dorado-García A, van Duijkeren E, van den Bunt G, Dierikx CM, Bonten MJM, et al. Attributable sources of community-acquired carriage of Escherichia coli containing $\beta$-lactam antibiotic resistance genes: a population-based modelling study. Lancet Planetary Health. 2019;3(8): e357-e69 https://doi.org/10.1016/S2542-5196(19)30130-5.

74. Evers EG, Pielaat A, Smid JH, van Duijkeren E, Vennemann FBC, Wijnands LM, et al. Comparative exposure assessment of ESBL-producing Escherichia coli through meat consumption. PLoS One. 2017;12(1):e0169589 https://doi. org/10.1371/journal.pone.0169589.

75. Dorado-García A, Smid JH, van Pelt W, Bonten MJM, Fluit AC, van den Bunt $\mathrm{G}$, et al. Molecular relatedness of ESBL/AmpC-producing Escherichia coli from humans, animals, food and the environment: a pooled analysis. J Antimicrob Chemother. 2017;73(2):339-47.

76. Day MJ, Hopkins KL, Wareham DW, Toleman MA, Elviss N, Randall L, et al. Extended-spectrum $\beta$-lactamase-producing Escherichia coli in humanderived and foodchain-derived samples from England, Wales, and Scotland: an epidemiological surveillance and typing study. Lancet Infect Dis. 2019; 19(12):1325-35 https://doi.org/10.1016/S1473-3099(19)30273-7.

77. de Been M, Lanza VF, de Toro M, Scharringa J, Dohmen W, Du Y, et al. Dissemination of cephalosporin resistance genes between Escherichia coli strains from farm animals and humans by specific plasmid lineages. PLoS Genet. 2014;10(12):e1004776 https://doi.org/10.1371/journal.pgen.1004776.

78. Berg ES, Wester AL, Ahrenfeldt J, Mo SS, Slettemeas JS, Steinbakk M, et al. Norwegian patients and retail chicken meat share cephalosporin-resistant Escherichia coli and IncK/blaCMY-2 resistance plasmids. Clin Microbiol Infect. 2017:23(6):407 e9-e15.

79. Mobley HL, Green DM, Trifillis AL, Johnson DE, Chippendale GR, Lockatell $\mathrm{CV}$, et al. Pyelonephritogenic Escherichia coli and killing of cultured human renal proximal tubular epithelial cells: role of hemolysin in some strains. Infect Immun. 1990;58(5):1281-9 https://doi.org/10.1128/IAl.58.5.1281-1289.1 990.

80. Lagesen K. NorwegianVeterinaryInstitute/Bifrost 2018-11-04 (version 201811-04); 2020.

81. Ewels P, Magnusson M, Lundin S, Kaller M. MultiQC: summarize analysis results for multiple tools and samples in a single report. Bioinformatics. 2016:32(19):3047-8 https://doi.org/10.1093/bioinformatics/btw354

82. Bolger AM, Lohse M, Usadel B. Trimmomatic: a flexible trimmer for Illumina sequence data. Bioinformatics. 2014;30(15):2114-20 https://doi.org/10.1093/ bioinformatics/btu170.

83. Bankevich A, Nurk S, Antipov D, Gurevich AA, Dvorkin M, Kulikov AS, et al. SPAdes: a new genome assembly algorithm and its applications to singlecell sequencing. J Comput Biol. 2012;19(5):455-77 https://doi.org/10.1089/ cmb.2012.0021.

84. Walker BJ, Abeel T, Shea T, Priest M, Abouelliel A, Sakthikumar S, et al. Pilon: An Integrated Tool for Comprehensive Microbial Variant Detection and Genome Assembly Improvement. PLoS One. 2014;9(11):e112963 https://doi. org/10.1371/journal.pone.0112963. PMID: 25409509; PMCID: PMC4237348.

85. Gurevich A, Saveliev V, Vyahhi N, Tesler G. QUAST: quality assessment tool for genome assemblies. Bioinformatics. 2013;29(8):1072-5 https://doi.org/1 0.1093/bioinformatics/btt086.

86. Lagesen K. NorwegianVeterinaryInstitute/Bifrost: 2019-09-05 (version 201909-05); 2020. 
87. Hunt M, Mather AE, Sanchez-Buso L, Page AJ, Parkhill J, Keane JA, et al. ARIBA: rapid antimicrobial resistance genotyping directly from sequencing reads. Microbial Genomics. 2017;3(10):e000131 https://doi.org/10.1099/ mgen.0.000131.

88. Wirth T, Falush D, Lan R, Colles F, Mensa P, Wieler LH, et al. Sex and virulence in Escherichia coli: an evolutionary perspective. Mol Microbiol. 2006;60(5):1136-51 https://doi.org/10.1111/j.1365-2958.2006.05172.x.

89. Zankari E, Hasman H, Cosentino S, Vestergaard M, Rasmussen S, Lund O, et al. Identification of acquired antimicrobial resistance genes. J Antimicrob Chemother. 2012;67(11):2640-4 https://doi.org/10.1093/jac/dks261.

90. Joensen KG, Scheutz F, Lund O, Hasman H, Kaas RS, Nielsen EM, et al. Realtime whole-genome sequencing for routine typing, surveillance, and outbreak detection of verotoxigenic Escherichia coli. J Clin Microbiol. 2014; 52(5):1501-10 https://doi.org/10.1128/JCM.03617-13.

91. Chen L, Yang J, Yu J, Yao Z, Sun L, Shen Y, et al. VFDB: a reference database for bacterial virulence factors. Nucleic Acids Res. 2005;33(Database issue): D325-8 https://doi.org/10.1093/nar/gki008.

92. Joensen KG, Tetzschner AM, Iguchi A, Aarestrup FM, Scheutz F. Rapid and easy in Silico serotyping of Escherichia coli isolates by use of wholegenome sequencing data. J Clin Microbiol. 2015;53(8):2410-26 https://doi. org/10.1128/JCM.00008-15.

93. Team RC. R: a language and environment for statistical computing. Vienna: R Foundation for Statistical Computing; 2014.

94. Silva M, Machado MP, Silva DN, Rossi M, Moran-Gilad J, Santos S, et al. chewBBACA: A complete suite for gene-by-gene schema creation and strain identification. Microb Genom. 2018:4(3):e000166 https://doi.org/10.1099/ mgen.0.000166. Epub 2018 Mar 15. PMID: 29543149; PMCID: PMC5885018.

95. Yu G, Smith DK, Zhu H, Guan Y, Lam TT-Y. Ggtree: an r package for visualization and annotation of phylogenetic trees with their covariates and other associated data. Methods Ecol Evol. 2017;8(1):28-36 https://doi.org/1 0.1111/2041-210X.12628.

96. Letunic I, Bork P. Interactive tree of life (iTOL) V3: an online tool for the display and annotation of phylogenetic and other trees. Nucleic Acids Res. 2016;44(W1):W242-W5 https://doi.org/10.1093/nar/gkw290.

97. Wu KH, Wang KC, Lee LW, Huang YN, Yeh KS. A constitutively mannosesensitive agglutinating Salmonella enterica subsp. enterica serovar typhimurium strain, carrying a transposon in the fimbrial usher gene stbC exhibits multidrug resistance and flagellated phenotypes. TheScientificWorldJ. 2012;2012:280264.

98. Tille PM, Forbes BA. Bailey \& Scott's diagnostic microbiology (thirteenth edition). Louis: Elsevier; 2014.

99. Stromberg ZR, Johnson JR, Fairbrother JM, Kilbourne J, Van Goor A, Curtiss $R R$, et al. Evaluation of Escherichia coli isolates from healthy chickens to determine their potential risk to poultry and human health. PLoS One. 2017; 12(7):e0180599 https://doi.org/10.1371/journal.pone.0180599.

100. Benge GR. Bactericidal activity of human serum against strains of Klebsiella from different sources. J Med Microbiol. 1988;27(1):11-5 https://doi.org/10.1 099/00222615-27-1-11.

101. Ammerman NC, Beier-Sexton M, Azad AF. Growth and maintenance of Vero cell lines. Curr Protoc Microbiol. 2008;Appendix 4:Appendix 4E https://doi. org/10.1002/9780471729259.mca04es11. PMID: 19016439; PMCID: PMC2657228. https://pubmed.ncbi.nlm.nih.gov/19016439/.

102. Calcuttawala F, Hariharan C, Pazhani GP, Ghosh S, Ramamurthy T. Activity spectrum of colicins produced by Shigella sonnei and genetic mechanism of colicin resistance in conspecific S. sonnei strains and Escherichia coli. Antimicrob Agents Chemother. 2015;59(1):152-8 https://doi.org/10.1128/AA C.04122-14.

\section{Publisher's Note}

Springer Nature remains neutral with regard to jurisdictional claims in published maps and institutional affiliations.

Ready to submit your research? Choose BMC and benefit from:

- fast, convenient online submission

- thorough peer review by experienced researchers in your field

- rapid publication on acceptance

- support for research data, including large and complex data types

- gold Open Access which fosters wider collaboration and increased citations

- maximum visibility for your research: over $100 \mathrm{M}$ website views per year

At BMC, research is always in progress.

Learn more biomedcentral.com/submissions 